\title{
Studies of Experimental Renal Failure in Dogs. I. Effect of 5/6 Nephrectomy on Concentrating and Diluting Capacity of Residual Nephrons *
}

\author{
Jack W. Coburn, † Harvey C. Gonick, Milton E. Rubini, and \\ Charles R. Kleeman $\ddagger$ \\ (From the Medical Service, Wadsworth Hospital, Veterans Administration Center, Los \\ Angeles, Calif., and the Departments of Medicine, UCLA Center for the \\ Health Sciences and Mount Sinai Hospital, Los Angeles, Calif.)
}

Two divergent theories have been offered to explain the concentrating and diluting defects of chronic renal disease. The conventional view attributes these abnormalities to damage to specific nephron sites and assumes a significant formation of urine by partially damaged nephrons. The alternative view postulates little or no function by damaged nephrons and attributes virtually all function to the remaining "intact nephrons." It is suggested that the increased solute excretion by these fewer normal nephrons interferes with the ability to concentrate and dilute urine $(1,2)$. This follows from the observations in normals, under conditions of both antidiuresis and water diuresis, that an increase in solute excretion causes urine osmolality to approach that of plasma (3-6).

Data supporting this latter thesis have been obtained in an animal model with unilateral kidney disease. When concentrating and diluting abilities were expressed at equivalent rates of glomerular filtration, these functions were approximately equal in the diseased and contralateral normal kidney $(2,7)$. However, extrapolation of such data to

* Submitted for publication June 4, 1964 ; accepted December 14, 1964.

Supported in part by U. S. Public Health Service grants (AM 01634-06 and APD 13952) and a Los Angeles County Heart Association grant (318).

Presented in part before the Sixteenth Annual Meeting of the Western Society for Clinical Research, February 1, 1963, Carmel, Calif.

† Work performed in part during tenure of U. S. Public Health Service postdoctoral research fellowship of the National Institute of Arthritis and Metabolic Diseases. Present address: Department of Metabolism, Walter Reed Army Institute of Research, Washington, D. C.

$\$$ Address requests for reprints to : Dr. Charles $\mathrm{R}$. Kleeman, Mount Sinai Hospital, 8720 Beverly Boulevard, Los Angeles 48, Calif. the interpretation of function in patients with bilateral kidney disease may not be valid. Not only does the design of such a model eliminate the altered physiology due to uremia, but the presence of the normal kidney may modify or abrogate stimuli causing anatomic and functional hypertrophy in the diseased kidney $(8,9)$. Experimental and clinical data that offer support and criticism of the intact nephron thesis are reviewed elsewhere (10-12).

It was the aim of the present experiments to study concentrating and diluting abilities in a kidney with a reduced number of intact nephrons. These functions were compared in dogs with renal mass surgically reduced by $5 / 6$ nephrectomy and in normal animals receiving a urea osmotic load. ${ }^{1}$ It was thus possible to compare the functions of the normal kidney and kidney remnant at comparable rates of solute excretion per nephron mass.

\section{Methods}

Thirty-five experiments were performed on twelve female mongrel dogs weighing from 9.5 to $18.4 \mathrm{~kg}$. In six dogs approximately five-sixths of the renal mass was removed by a two-stage surgical procedure. At the first procedure, both poles of one kidney were resected, and the larger of the main renal artery branches of the other kidney was ligated. Two and one-half weeks later, the hemi-infarcted kidney was removed. In order to estimate the proportion of renal tissue removed, a similar bipolar resection and contralateral nephrectomy were

1 Urea osmotic diuresis was chosen since urea is responsible for most of the increased osmotic load per nephron in chronic renal disease. (Although sodium and its attendant anions must also be excreted in increased quantities by each remaining nephron, the possibility of extracellular fluid expansion and cardiovascular alterations militates against the administration of saline as the osmotic agent.) 


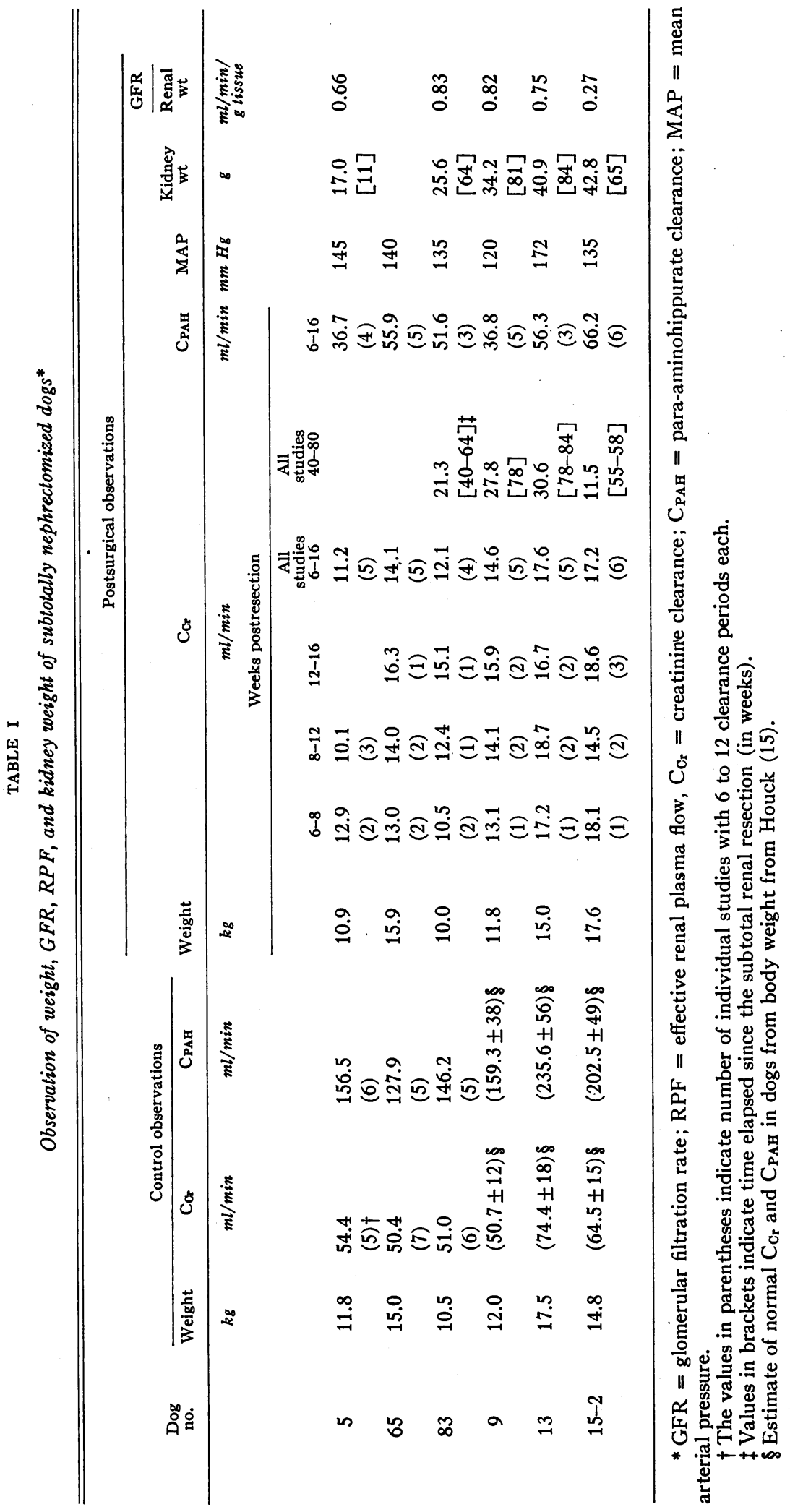


performed in a one stage procedure in four additional animals that were not studied. The weight of the resected poles was 57 to $66 \%$ of the contralateral kidney weight, and the remaining mass was 18 to $22 \%$ of total preoperative kidney weight. Surgical details have been reported elsewhere (13).

All animals were maintained on a constant canned dog food diet that gave $9 \mathrm{~g}$ of protein for each $\mathrm{kg}$ of body weight, and the experiments were performed in the unanesthetized state after a 22 - to 24-hour fast. The animals were trained to stand in a frame, loosely supported by a canvas sling. Urine samples were obtained through a soft, multiholed, indwelling catheter; adequacy of collection was assured by suprapubic compression plus two or three air washouts when urine flow was below $5 \mathrm{ml}$ per minute. Blood samples were obtained at appropriate intervals from an indwelling needle inserted into a foreleg vein, and infusions were administered with a constant infusion pump into a rear leg vein.

Exogenous creatinine clearance was employed as a measure of glomerular filtration rate (GFR), and paraaminohippurate (PAH) clearance as a measure of effective renal plasma flow (RPF). Creatinine and PAH determinations were done by standard methods $(14,15)$, urea nitrogen by a modified method of Kibrick, Ross, and Scupp (16) or the method of Skeggs (17). Plasma and urine osmolality were measured by freezing point depression.

Similar experiments were done in six animals after the above described subtotal (5/6) nephrectomy: in three of these animals, control studies were performed before operation, but in the other three there were no preoperative studies.

After 5/6 nephrectomy, all animals appeared healthy, ate well, and maintained their weight. Initial studies were performed between 6 and 16 weeks after the second operative procedure. For the entire group of animals, the mean GFR remained stable and did not vary significantly during the 6- to 16-week period after surgery ( $p>0.10$ by variance analysis (18) as shown in Table $\mathrm{I}$, although in three individual animals (dogs 65,83 , and 9) there was an increase in GFR. Mean filtration rates were 24,28 , and $29 \%$, and effective renal plasma flow rates (PAH clearances) were 23,43 , and $35 \%$ of control values, respectively, in the three animals studied before surgery. Although only a very crude estimate of functional renal mass remaining, filtration rates in three other animals not studied preoperatively were 29,27 , and $24 \%$ of "normal" values predicted from the body weight (19). These similarities indicate a high

TABLE II

Maximal and minimal urinary osmolalities in normal and 5/6 nephrectomized dogs

\begin{tabular}{|c|c|c|c|c|c|c|c|}
\hline \multirow[b]{3}{*}{ Dog } & \multirow{2}{*}{\multicolumn{2}{|c|}{ Normal }} & \multirow[b]{3}{*}{ Dog } & \multicolumn{4}{|c|}{ 5/6 Nephrectomy } \\
\hline & & & & \multicolumn{2}{|c|}{ 6-16 weeks* } & \multicolumn{2}{|c|}{ 40-80 weeks* } \\
\hline & $\begin{array}{l}\text { Uosm } \\
\text { Max }\end{array}$ & $\begin{array}{l}\text { Uoam } \\
\text { Min }\end{array}$ & & $\begin{array}{l}\text { Uosm } \\
\text { Max }\end{array}$ & $\begin{array}{l}\text { Uosm } \\
\text { Min }\end{array}$ & $\begin{array}{l}\text { Uosm } \\
\operatorname{Max}\end{array}$ & $\begin{array}{l}\text { Uosm } \\
\text { Min }\end{array}$ \\
\hline & \multicolumn{2}{|c|}{$m O s m / k g$} & & \multicolumn{2}{|c|}{$\mathrm{mOsm} / \mathrm{kg}$} & \multicolumn{2}{|c|}{$m O s m / k g$} \\
\hline $5 \ddagger$ & 1,296 & 51 & $5 \ddagger$ & 896 & 78 & & \\
\hline $65 \ddagger$ & 2,028 & 66 & $65 \ddagger$ & 765 & 91 & & \\
\hline $83 \ddagger$ & . 1,888 & 39 & $83 \ddagger$ & 1,268 & 108 & 1,579 & 66 \\
\hline $12 \ddagger$ & 1,619 & 49 & $9 t$ & 966 & 57 & 1,252 & \\
\hline T1f & 1,381 & 42 & $13 \ddagger$ & 1,510 & 58 & & \\
\hline $4 \ddagger$ & 1,889 & 41 & $15-2 \ddagger$ & 694 & 71 & 570 & 146 \\
\hline $3 \ddagger$ & 1,288 & 34 & & & & & \\
\hline $85 \ddagger$ & 1,296 & 97 & & & & & \\
\hline $\mathrm{C}_{2}$ & 1,807 & 63 & & & & & \\
\hline $\mathrm{M}$ & 1,937 & & & & & & \\
\hline $\mathrm{G}$ & 1,435 & & & & & & \\
\hline $\mathbf{H}$ & 1,314 & & & & & & \\
\hline $\mathbf{K}$ & 1,565 & & & & & & \\
\hline $\mathrm{N}$ & 1,751 & & & & & & \\
\hline$Q$ & 1,776 & & & $\cdot$ & & & \\
\hline $\mathrm{R}$ & 1,527 & & & & & & \\
\hline $\mathrm{L}_{2}$ & 1,493 & & & & & & \\
\hline $\mathrm{A}_{2}$ & 1,292 & & & & & & \\
\hline No. & 18 & 9 & & 6 & 6 & & \\
\hline Mean & 1,588 & 48.0 & & 1,016 & 77.2 & & \\
\hline $\mathrm{SD}$ & 256 & 10.5 & & 314 & 19.7 & & \\
\hline$t$ & & & & $\mathrm{p}<.001$ & $\mathrm{p}<.01$ & & \\
\hline
\end{tabular}

* Time lapse after 5/6 nephrectomy.

$\dagger$ Urinary osmolality.

¥ Subjected to subsequent urea infusions with data included in Figures 1 to 6 . 


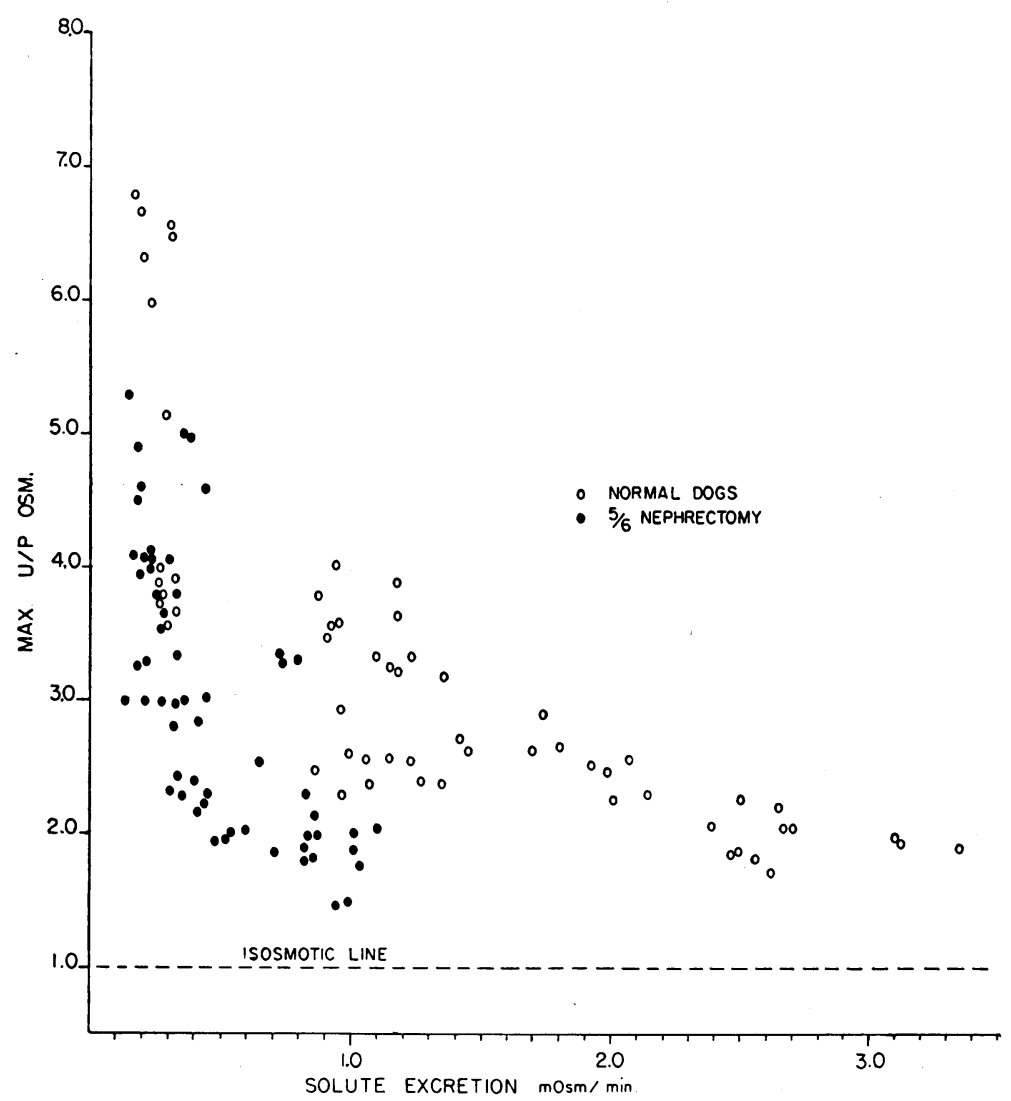

Fig. 1. EFfect of increase in SOLUte excretion on maximal URINe/ PLASMA (U/P) OSMOLAL RATIOS IN CONTROL AND 5/6 NEPHRECTOMIZED DOGS. Each symbol represents a collection period.

degree of reproducibility of the surgical reduction of renal mass. Two animals (no. 5 and 65) died 11 and 12 weeks after the second operative procedure during anesthesia for another study. The four other animals were sacrificed 40 to 84 weeks after surgery. During this later period ( 40 to 84 weeks after surgery) filtration rates were greater than the earlier values in three animals. The kidneys of all were hypertrophied with usually one large renal pyramid remaining. Histologic sections in five revealed glomerular and tubular hypertrophy that was more marked in those sacrificed later. There were rare foci of lymphocytic infiltration and focal basement membrane thickening in a few glomeruli. In the sixth animal (dog no. 15-2), proteinuria appeared between 18 and 40 weeks after operation, and a decrease in GFR was noted. Functional changes in this animal are described in detail below. Histologic examination revealed marked tubular dilatation extending into the proximal tubules and Bowman's space with interstitial fibrosis and chronic inflammation, probably secondary to intrarenal obstruction due to constrictive capsular scarring.

Antidiuresis studies. Maximal antidiuresis was achieved by 16 to 18 hours of water deprivation and the infusion of aqueous vasopressin (Pitressin, diluted from a fresh ampoule before each experiment) at a rate of 50 $\mathrm{m} \mu$ per $\mathrm{kg}$ per hour. After allowing 30 to 45 minutes equilibration of priming and sustaining solutions, three urine collections of 30 to 45 minutes duration were made at basal rates of solute excretion in 18 normal dogs to determine maximal urine/plasma. (U/P) osmolal ratios. Urea was then given to nine of these animals to produce elevation of blood levels to approximately four and then eight times normal by two priming infusions of 75 mmoles each, followed by a sustaining solution delivering first 1 mmole and then 2 mmoles per minute, respectively. In some experiments, an intermediate level was achieved by increasing the sustaining level to 2 mmoles per minute several periods before the second priming infusion. At each level of blood urea, three specimens of urine were obtained over periods of 12 to 20 minutes. Experiments performed after subtotal resection were similar to those in the normals except that urea was usually infused at only the lower rate.

Water diuresis studies. Water intake was unrestricted before the experiment. Water diuresis was induced by a water load of $4 \%$ of body weight given by stomach tube and maintained by intravenous infusion of $2 \frac{1}{2} \%$ dextrose in water administered at a rate equal to urine flow with 
an additional 40 to $50 \mathrm{ml}$ given per hour for loss via lungs and mucous membranes. Exogenous creatinine and $\mathrm{PAH}$ clearances with urea infusions were performed as in the dehydration studies. Urinary collection periods were initiated only after urine flow had reached a constant rate for two or three periods ( 90 to 210 minutes after the water load). The possibility of secretion of endogenous antidiuretic hormone during urea infusion cannot be absolutely excluded; however, the degree of depression of urinary osmolality, the increase in free water clearance with the rise in solute excretion, and the absence of any sudden change in osmolality make such antidiuretic hormone release highly unlikely.

\section{Results}

Antidiuresis studies. At basal rates of solute excretion (150 to $300 \mu$ Osm per minute), there was a significant decrease in maximal urinary osmolality in the subtotally nephrectomized animals. The maximal urinary osmolalities indicated in Table II are the highest observed during any of several collection periods during the initial ( 6 to 12 weeks postoperative) antidiuresis experiments. The mean maximal urinary osmolality of the kidney remnant animals differs significantly from that of 18 normal dogs similarly studied ( $\mathrm{p}<0.001$ ).

As solute excretion increased, the anticipated rise in urine flow and fall in osmolality was observed in both groups of animals. The maximal $\mathrm{U} / \mathrm{P}$ osmolal ratios achieved at all observed solute excretion rates were greater in the normals than in the $5 / 6$ nephrectomized animals (Figure 1). Rates of free water reabsorption ( $\mathrm{T}^{\mathrm{c}} \mathrm{H}_{2} \mathrm{O}$ ) increased in both experimental groups with increased solute excretion approaching, but generally below, maximal rates $(\mathrm{Tm})$. The $\mathrm{T}^{\mathrm{c}}{ }_{\mathrm{H}_{2} \mathrm{O}}$ rates of normals exceeded those of the 5/6 nephrectomized dogs at similar solute excretion rates, although the differences were not marked. Because the total osmotic load imposed on the kidney remnant animals was generally below that in the normal, they may be strictly compared in only a fraction of the collection periods.

Since both the rate of solute excretion $\left(\mathrm{U}_{0 \mathrm{sm}} \mathrm{V}\right)$ and elaboration of $\mathrm{T}^{c_{H_{2}}}$ Occur in far fewer nephrons in the subtotally nephrectomized animals, a correction factor for functional mass was applied to both parameters. Within limitations discussed

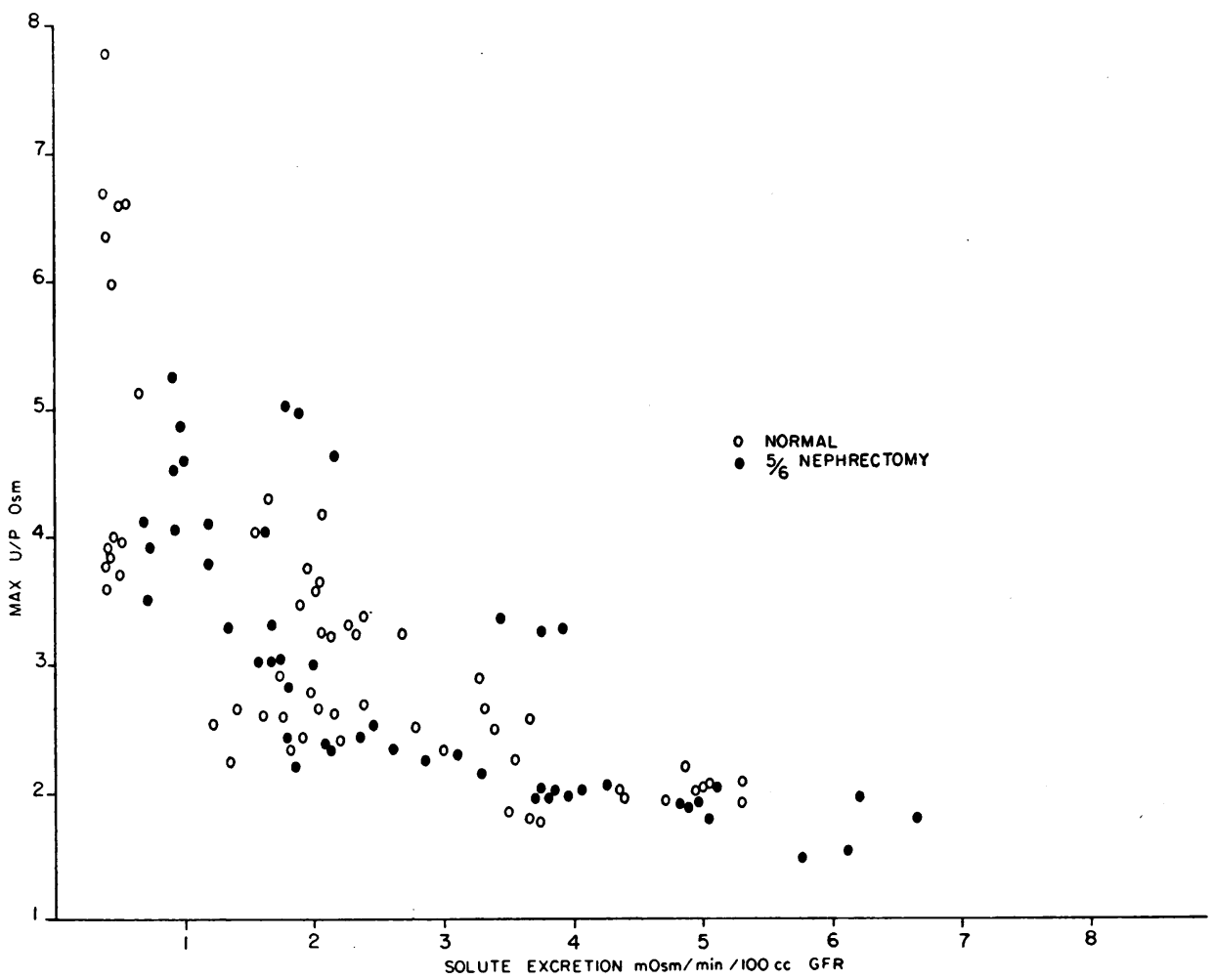

Fig. 2. EFFect of “CORRECTED" solute excRetion (UoamV/GFR $\times 100$ ) on maximal U/P OSMOLAL RATIOS IN NORMAL AND 5/6 NEPHRECTOMIZED ANIMALS. 


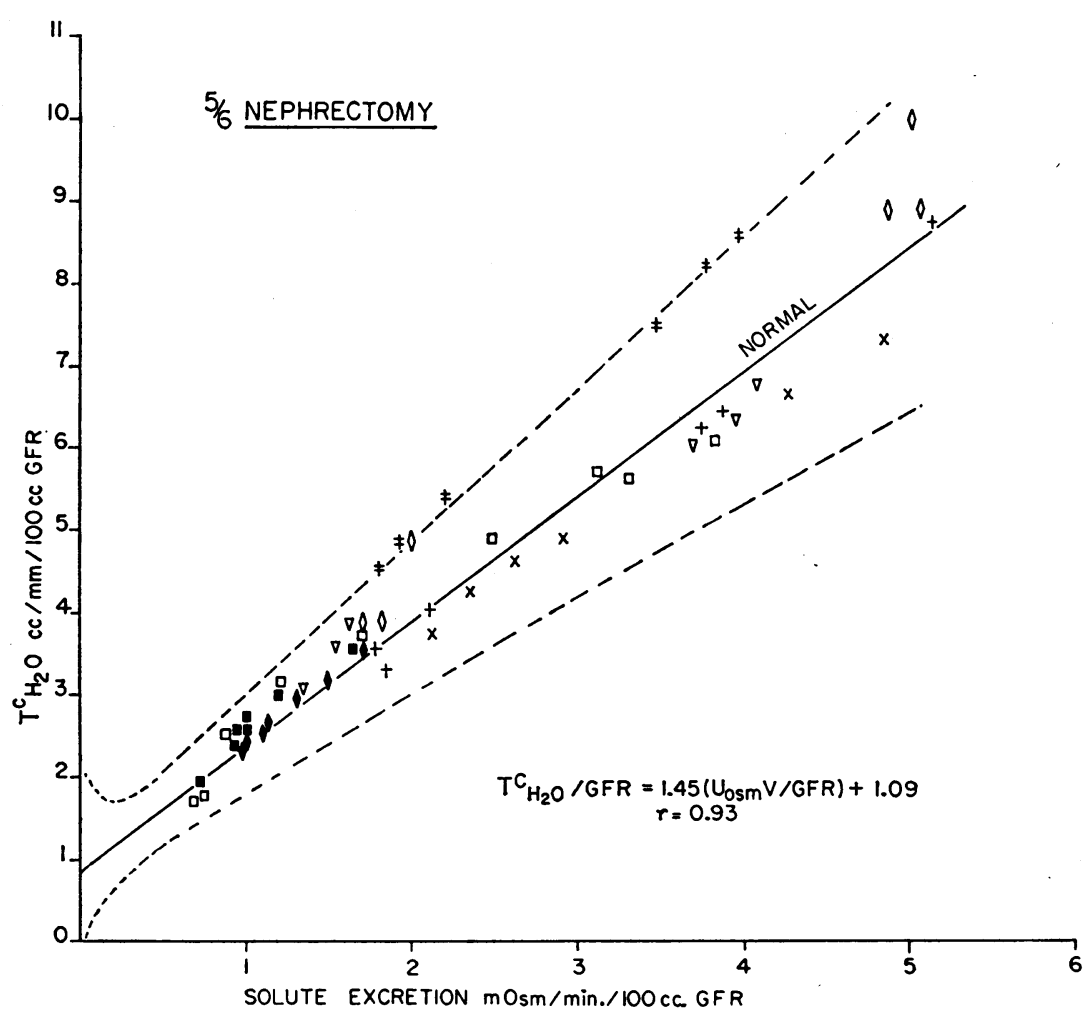

Fig. 3. EFFECT OF INCREASING SOLUTE EXCRETION ON FREE WATER REABSORPTION ( $\mathrm{T}^{\mathrm{e}}{ }_{\text {H2O }}$ ) WHEN BOTH ARE "CORRECTED" TO RENAL MASS AND EXPRESSED PER $100 \mathrm{ML}$ OF GLOMERULAR FILTRATE AFTER 5/6 NEPHRECTOMY. The regression slope and $95 \%$ confidence limits from the normal group are superimposed on the data from $5 / 6$ nephrectomized animals. Individual experiments in each animal are indicated by the following symbols in Figures 3 and 6.

\begin{tabular}{ccccrrr}
\multicolumn{3}{c}{ Dog no. } & \multicolumn{4}{c}{ Dog no. } \\
5 & $(7)^{*}$ & $\nabla$ & & 83 & $(60)$ & \\
$15-2$ & $(8)$ & + & 9 & $(8)$ & $\diamond$ \\
65 & $(6)$ & $\times$ & 9 & $(78)$ & $\diamond$ \\
83 & $(7)$ & $\square$ & 13 & $(7)$ & $\neq$
\end{tabular}

* The number in parentheses indicates time (in weeks) after surgery.

below, the GFR has been utilized as the estimate of functioning renal mass. In these "corrected" comparisons, both solute excretion and $\mathrm{T}^{\mathrm{c}} \mathrm{H}_{2} \mathrm{O}$ are expressed per $100 \mathrm{ml}$ of glomerular filtrate (i.e.,

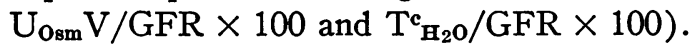

When maximal $U / P$ osmolal ratios of control and partially nephrectomized animals are compared at adjusted solute excretion rates $\left(\mathrm{U}_{\mathrm{Osm}} \mathrm{V} /\right.$ GFR), the two groups are similar (Figure 2). Likewise, when $\mathrm{T}^{\mathrm{c}}{ }_{\mathrm{H}_{2} \mathrm{O}}$ /GFR was compared at adjusted solute excretion rates, the $5 / 6$ nephrectomized animals did not differ from controls (Figure 3).

With further increases in the rate of solute excretion to above 6 mOsm per minute per GFR $\times 100, \mathrm{~T}^{\mathrm{c}} \mathrm{H}_{2} \mathrm{O} / \mathrm{GFR}$ approached the maximal rate of free water absorption $\left(\mathrm{T}_{\max }^{\mathrm{c}} \mathrm{H}_{2} \mathrm{O}\right)$. As the number of collection periods with adjusted solute loads above $6 \mathrm{mOsm}$ per minute GFR $\times$ 100 was small, these have been excluded from graphic and statistical representation. Linear regression slopes have been calculated from the remaining data. A modified statistical method for testing equality between sets of coefficients of two linear regressions adopted from Chow (20) was utilized to test the hypothesis that the slopes of the two regression lines were equal. No significant difference was found between the two regression 
slopes: 1) normal:

$\frac{\mathrm{T}^{\mathrm{c}} \mathrm{H}_{2} \mathrm{O}}{\mathrm{GFR}} \times 100=1.548\left(\frac{\mathrm{U}_{\mathrm{Osm}} \mathrm{V}}{\mathrm{GFR}} \times 100\right)+0.834$ and 2) $5 / 6$ nephrectomy:

$\frac{\mathrm{T}^{\circ}{ }_{\mathrm{H}_{2} \mathrm{O}}}{\mathrm{GFR}} \times 100=1.433\left(\frac{\mathrm{U}_{\mathrm{Osm} \mathrm{V}}}{\mathrm{GFR}} \times 100\right)$ $+1.134(\mathrm{p}=0.10) .^{2}$

Water diuresis studies. The $5 / 6$ nephrectomized animals demonstrated an impaired ability to lower minimal U/P osmolal ratios during a sustained water diuresis at both basal solute excretion rates (Table II) and at the increased rates of solute excretion observed after urea administration (Figure 4). The kidney remnant group also had reduced free water clearance rates $\left(\mathrm{C}_{\mathbf{H}_{2} \mathrm{O}}\right)$ in the range of solute excretion observed. On the other hand, when $\mathrm{C}_{\mathrm{H}_{2} \mathrm{O}}$ was corrected to functional mass $\left(\mathrm{C}_{\mathrm{H}_{2} \mathrm{O}} / \mathrm{GFR} \times 100\right)$ and plotted against adjusted rates of solute excretion ( $U_{\text {osm }} V / G F R \times$ 100 ), the $5 / 6$ nephrectomized animals demon-

2 This statistical comparison was kindly performed by Edward F. Gocka, Western Research Support Center, Sepulveda Veterans Administration Hospital, Sepulveda, Calif. strated lower U/P osmolal ratios (Figure 5) and enhanced ability to elaborate free water (Figure 6).

Although the relationship between the rate of $\mathrm{C}_{\mathrm{H}_{2} \mathrm{O}}$ and solute excretion is not linear, $\mathrm{C}_{\mathrm{H}_{2} \mathrm{O}}$ approaches a maximum $\left(\mathrm{C}_{\max } \mathrm{H}_{2} \mathrm{O}\right)$, and the relationship has been considered linear for purposes of defining statistical limits. As in the antidiuresis studies, the data for collection periods with adjusted solute excretion above $6 \mathrm{mOsm}$ per minute per GFR $\times 100$ have been excluded. The difference between slopes of the two linear equations: 1 ) normal:

$\frac{\mathrm{C}_{\mathrm{H}_{2} \mathrm{O}}}{\mathrm{GFR}} \times 100=1.388\left(\frac{\mathrm{U}_{\mathrm{Osm}} \mathrm{V}}{\mathrm{GFR}} \times 100\right)+5.69$

and 2) 5/6 nephrectomy:

$\frac{\mathrm{C}_{\mathrm{H}_{2} \mathrm{O}}}{\mathrm{GFR}} \times 100=1.950\left(\frac{\mathrm{U}_{\mathrm{Osm}_{\mathrm{m}} \mathrm{V}}}{\mathrm{GFR}} \times 100\right) \times 8.793$

is significant at the 0.01 level of probability, and the difference between $\mathrm{Y}$ intercepts is very highly significant $(t=9.30, \mathrm{p}<0.001) .^{3}$

3 Statistical methods are similar to those described in antidiuresis studies $(18,20)$.

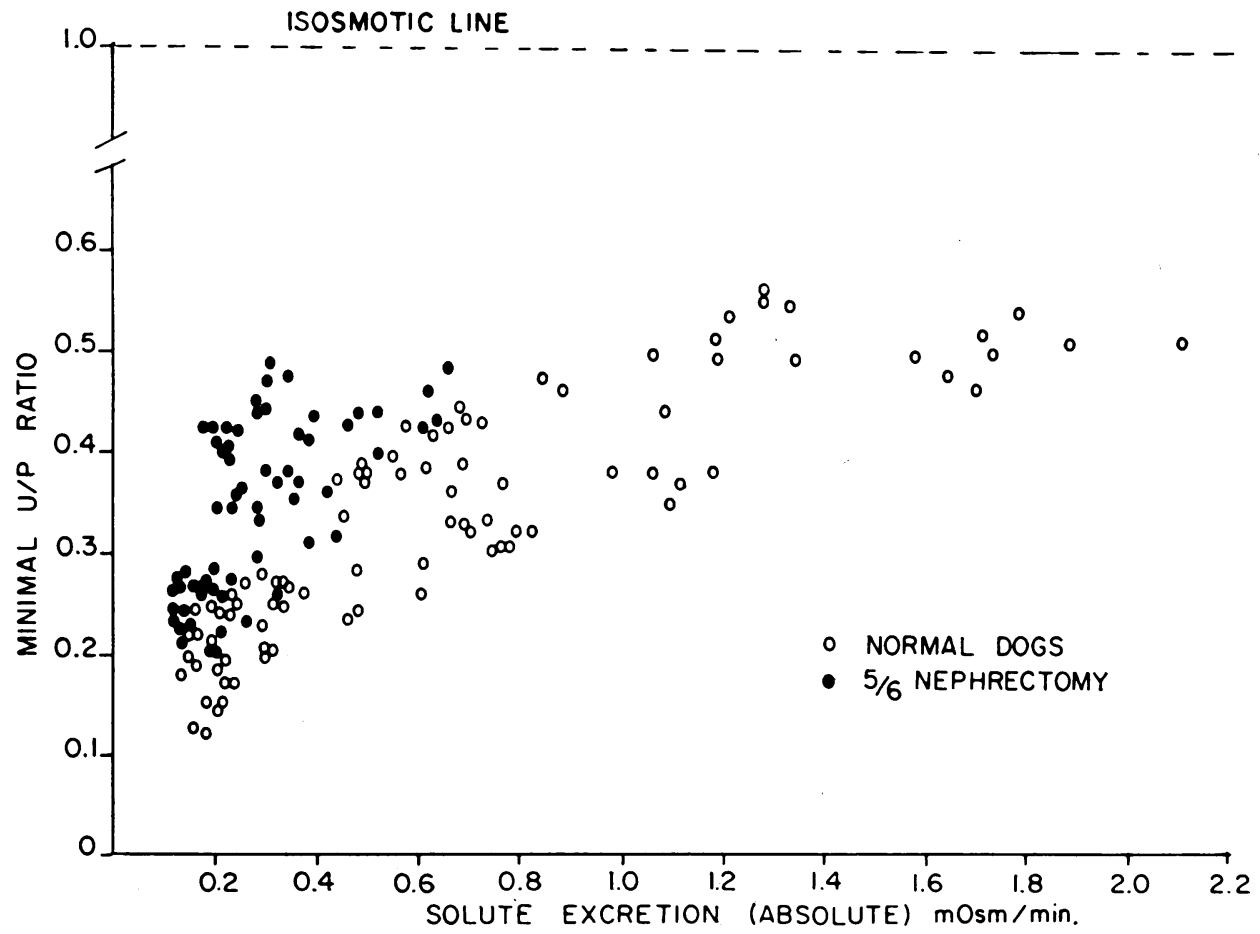

Fig. 4. EFfect OF INCREASING ABSOLUTE SOlUte EXCRETION RATE ON MiNimal U/P OSMOLAL RATIOS IN NORMAL AND 5/6 NEPHRECTOMIZED DOGS. 


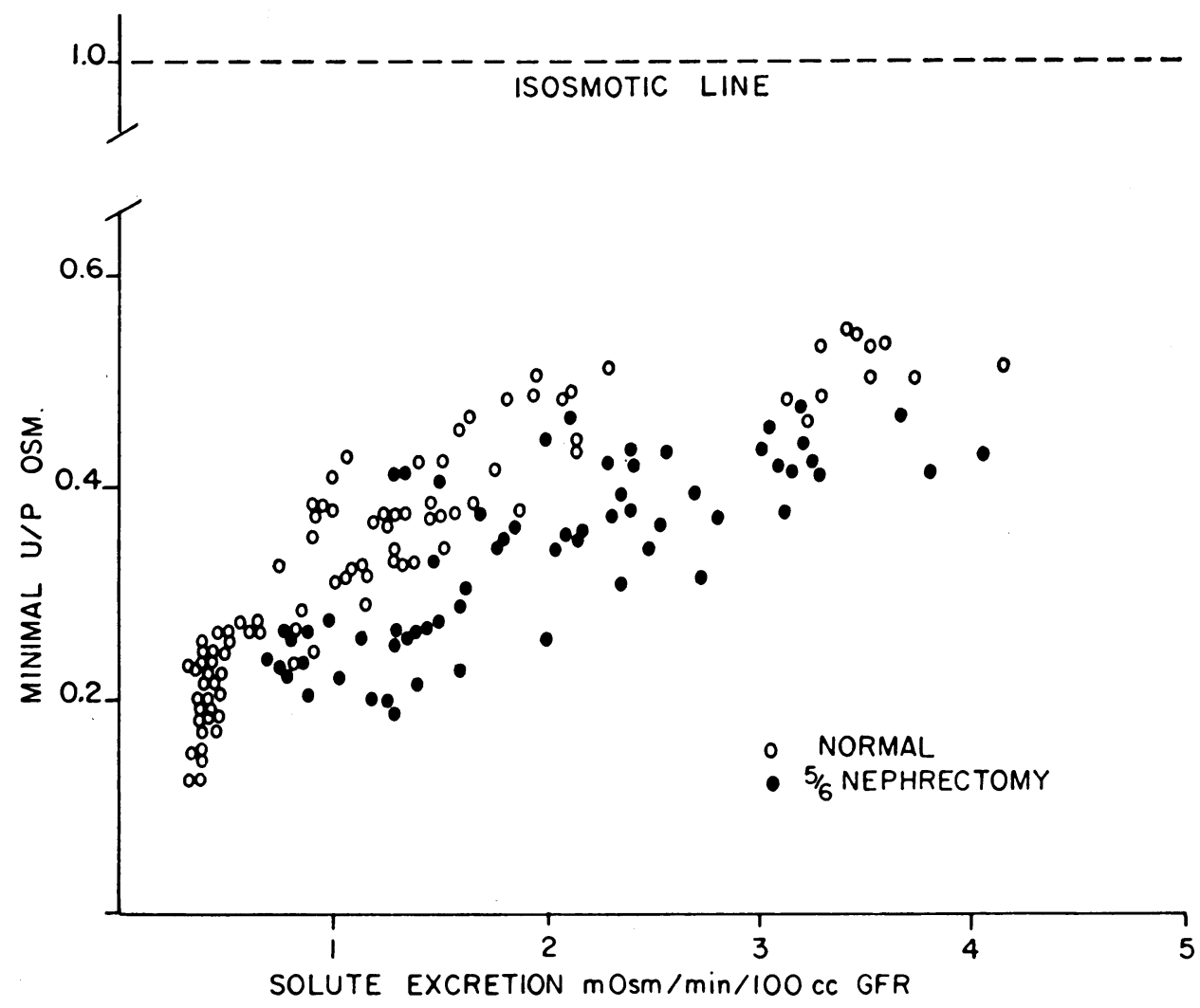

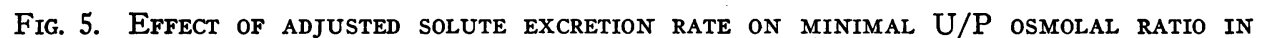
NORMAL AND 5/6 NEPHRECTOMIZED ANIMALS.

In contrast to these data, rather striking differences were noted in one animal that developed intrarenal pathology after the initial studies had been completed (dog no. 15-2). There was further impairment of concentrating ability and ability to achieve minimal U/P osmolality. When compared with the initial values in this animal, both concentrating and diluting functions were below observations made during the initial period (Table II). Values for $\mathrm{T}^{\mathrm{c}}{ }_{\mathrm{H}_{2} \mathrm{O}} / \mathrm{GFR}$ fell below the normal range, and those for $\mathrm{C}_{\mathrm{H}_{2} \mathrm{O}}$ /GFR were among those found in normals. With ethyl alcohol administration, $\mathrm{C}_{\mathrm{H}_{2} \mathrm{O}} / \mathrm{GFR}$ was not improved; hence, an increased level of antidiuretic hormone activity was probably not responsible for the progressive decrease in diluting ability observed with the development of intrarenal obstruction and interstitial fibrosis.

\section{Discussion}

Our data confirm findings of Bradford (21), Hayman, Shumway, Dumke, and Miller (22), and Platt, Roscoe, and Smith (23), who demonstrated that subtotally nephrectomized animals were unable to achieve normal maximal urinary specific gravity after dehydration. The present study also demonstrates that the capacity to dilute urine during a sustained water load is significantly impaired by reduction of renal mass. As it is likely that the great majority of residual nephrons were anatomically intact, it may be presumed that the increased solute load per remaining nephron is largely responsible for both the abnormal diluting and concentrating capacities. The maximal urinary concentrations are identical in normal and subtotally nephrectomized animals when they are compared at equivalent solute loads. On the other hand, when the capacity to dilute urine is expressed in a similar manner, the kidney remnant animals demonstrate greater diluting ability than normal.

Several limitations exist in using GFR to equate the two groups. The filtration rate per individual nephron undoubtedly increases after $5 / 6$ nephrectomy with the GFR reaching 24 to $29 \%$ of con- 
trol values during the initial study period (6 to 12 weeks) after only 18 to $22 \%$ of renal mass remained after surgery. Thus, one-sixth of the initial renal mass filters 50 to $60 \%$ more than that initially predicted, and this reaches 250 to $400 \%$ at the later period ( 40 to 80 weeks). These increases are associated with glomerular diameters 125 and $150 \%$ greater, respectively, than those in the kidney before resection. At least $50 \%$ more solute is filtered by each residual nephron when compared to controls on the basis of GFR, and changes in $\mathrm{C}_{\mathrm{H}_{2} \mathrm{O}} / \mathrm{GFR}$ and $\mathrm{T}^{\mathrm{c}} \mathrm{H}_{2} \mathrm{O} / \mathrm{GFR}$ probably represent changes in glomerular-tubular balance, at most. Kolberg demonstrated a shift of glomerular-tubular balance toward tubular preponderance (indicated by a decrease in the ratio of inulin clearance to maximal PAH transport) after 50 and $75 \%$ renal resection (24), and the increase in $\mathrm{C}_{\mathrm{H}_{2} \mathrm{O}}$ /GFR after $5 / 6$ nephrectomy may indicate a similar preponderance of distal tubular over glomerular function. It is assumed, in addition, that measured solute excretion per GFR is a similarly appropriate estimate of the various solutes reaching the concentrating and diluting sites in both groups of animals. As there was always greater obligate total sodium excretion per nephron in the kidney remnant animals, ratios of nonurea to urea solute were never equal when the two were compared at similar rates of solute excretion per functioning mass. Within the limitations imposed by these assumptions, these studies indicate a normal glomerular-tubular balance with

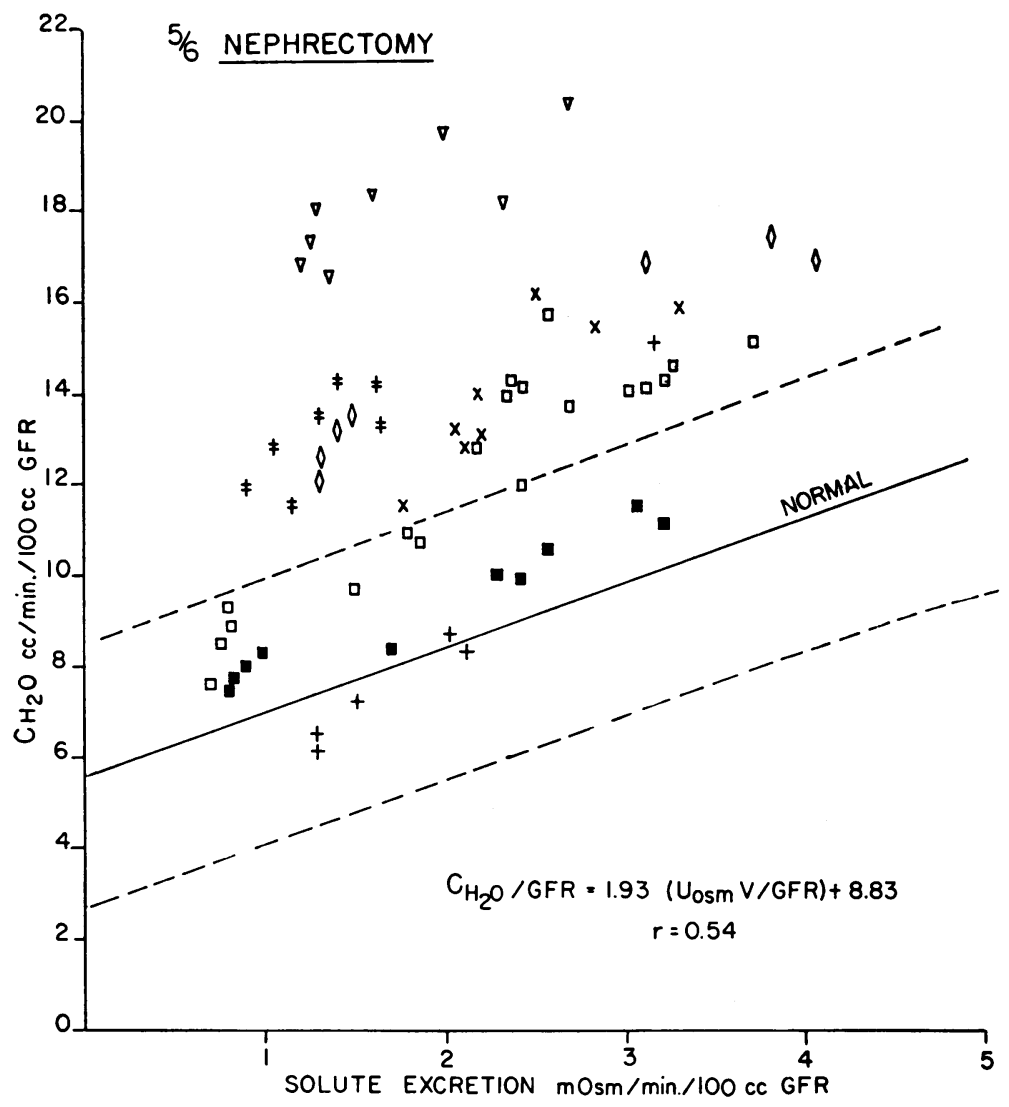

Fig. 6. EFFECT OF INCREASING SOLUTE EXCRETION RATE ON FREE WATER CLEARANCE WHEN BOTH ARE CORRECTED TO RENAL MASS AND EXPRESSED PER $100 \mathrm{ML}$ of glomerular filtrate. The normal regression slope and 95\% confidence limits are superimposed on the data from the $5 / 6$ nephrectomized dogs for comparison. Individual animals are indicated by symbols as shown in Figure 3, and the water diuresis studies were performed 3 to 4 weeks after times indicated for each symbol in Figure 3. 
respect to concentrating ability and a tendency toward enhanced tubular diluting capacity after reduction of normal nephron mass.

These data differ substantially from observations in patients with function reduced by bilateral parenchymal disease when concentrating and diluting functions are related to GFR. With the exceptions of studies in chronic glomerulonephritis by Baldwin, Berman, Heinemann, and Smith (25), observations in patients with chronic renal disease have demonstrated impaired concentrating ability as measured by $\mathrm{T}^{\mathrm{c}}{ }_{\max } \mathrm{H}_{2} \mathrm{O} / \mathrm{GFR}$ or maximal U/P osmolal ratios compared at equivalent adjusted solute excretion rates $(26,27)$. After removal of the intact kidney in dogs with unilateral renal disease, Bricker and co-workers have reported decreased maximal U/P osmolal ratios (28) and a reduction of $\mathrm{T}^{\mathrm{c}}{ }_{\max } \mathrm{H}_{2} \mathrm{O} / \mathrm{GFR}$ (29). With maneuvers to reduce filtered solute load, Hayman and associates noted an increase in maximal urine specific gravity in subtotally nephrectomized dogs to values approaching preoperative controls (22). In humans with chronic renal disease, Franklin, Niall, and Merrill found no increase in maximal urinary osmolality after reduction of the filtered solute load by hemodialysis or hypotension (30). These data indicate that factors other than solute load per nephron are important in the impaired concentrating ability of patients with chronic renal disease.

During maximal water diuresis, patients with a variety of chronic renal diseases achieve both normal minimal U/P osmolal ratios and $\mathrm{C}_{\mathrm{H}_{2} \mathrm{O}}$ / GFR at adjusted solute loads $(27,31)$. It has been suggested from such data that the abnormal diluting capacity in renal disease results from the increased solute load per nephron. The behavior of the subtotally nephrectomized animals, as a more appropriate guide to functional capacity of a reduced number of normal nephrons under increased load, indicates enhanced diluting ability; therefore, such an interpretation in chronic renal disease may not be entirely warranted.

Although a critical analysis of the factors responsible for the increased $\mathrm{C}_{\mathrm{H}_{2} \mathrm{O}} / \mathrm{GFR}$ is beyond the scope of this study, several hypotheses may be briefly examined. First, a change in the quantity or quality of solute reaching the distal nephron may alter $\mathrm{C}_{\mathrm{H}_{2} \mathrm{O}} \mathrm{O}$ GFR without the necessity of invoking increased tubular function. Increased filtration and decreased reabsorption of filtered sodium must occur in each residual nephron, and any increase in reabsorption of such sodium presented to distal diluting sites would increase $\mathrm{C}_{\mathrm{H}_{2} \mathrm{O}} / \mathrm{GFR} .^{4}$

Second, there may be augmented transport of available sodium by hyperplastic tubular cells in a manner analogous to the increased $\mathrm{Tm}_{\mathrm{PAB}} / \mathrm{C}_{\mathrm{In}}$ reported by Kolberg (24). Observations by Bricker and co-workers that the GFR of a unilateral diseased kidney increases abruptly on removal of the contralateral normal kidney (9) indicate that many alterations in function may be independent of the gradual hypertrophy observed after reduction of renal mass. The progressive increase in GFR with concomitant changes in $\mathrm{C}_{\mathrm{H}_{2} \mathrm{O}}$ and $\mathrm{T}^{\mathrm{c}} \mathrm{H}_{2} \mathrm{O}$ between 12 and 40 weeks in two animals suggests a further gradual adaptive reorganization of function with maintenance of tubular preponderance of diluting function. As the quantity of sodium transported from the cortical distal tubules probably greatly exceeds that moving into the medullary interstitium, only the change in $\mathrm{C}_{\mathrm{H}_{2} \mathrm{O}} / \mathrm{GFR}$ might be detected by clearance techniques.

Changes in $\mathrm{T}^{\mathrm{c}}{ }_{\mathrm{H}_{2} \mathrm{O}} / \mathrm{GFR}$ may occur as a result of alterations in blood flow to the kidney. An increase in medullary blood flow probably accompanies the rise in blood flow occurring per nephron after partial nephrectomy (32). Since an inverse relationship presumably exists between medullary blood flow and the hypertonicity of the medullary interstitium (33), a "wash-out" effect could reduce $\mathrm{T}_{\mathrm{H}_{2} \mathrm{O}}^{\mathrm{O}} / \mathrm{GFR}$ and counteract the factors mentioned above. The administration of aminophylline, which increases renal blood flow (34), is accompanied by an increase in $\mathrm{C}_{\mathrm{H}_{2} \mathrm{O}}$ / GFR (35) and a reduction of $\mathrm{T}^{\mathrm{c}} \mathrm{H}_{2} \mathrm{O} / \mathrm{GFR}$ (36).

Finally, increased rapidity of flow of tubular fluid through the loop of Henle might result in reduced passive diffusion of water from the descending limb of Henle's loop into the hypertonic medulla and also reduce back diffusion of water from the distal tubule and collecting duct (assuming some degree of back diffusion normally

4 The total sodium excreted per nephron under conditions of constant sodium intake must be increased, although with the greatly increased filtered sodium per nephron the percentage of filtered sodium reabsorbed may be actually higher in the residual nephrons (28). 
occurs in the absence of antidiuretic hormone) with increased $\mathrm{C}_{\mathrm{H}_{2} \mathrm{O}}$ /GFR likely in either instance. The present study does not allow discrimination between these various alternatives.

\section{Summary}

The effect of increased osmotic load on concentrating and diluting abilities was studied in dogs before and after resection of five-sixths of the renal mass. During maximal antidiuresis and sustained water diuresis graded infusions of urea were given to normal and $5 / 6$ nephrectomized dogs in order to compare these functions at the same solute load per functioning mass (as indicated by glomerular filtration rate). There was impairment of both maximal and minimal urine/plasma (U/P) osmolal ratios at basal and at increased solute excretion rates in the kidney remnant animals. When solute load was expressed per functioning renal mass in the two groups, the subtotally nephrectomized dogs had normal maximal $U / P$ osmolal ratios and enhanced minimal $\mathrm{U} / \mathrm{P}$ osmolal ratios compared with normal. The adjusted rates of free water clearance $\left(\mathrm{C}_{\mathrm{H}_{2} \mathrm{O}} / \mathrm{GFR}\right)$ and of free water reabsorption ( $\mathrm{T}^{\mathrm{c}} \mathrm{H}_{2} \mathrm{O} / \mathrm{GFR}$ ) were increased and equal to normal, respectively, after $5 / 6$ nephrectomy. These findings differ from observations in patients with functional mass reduced by diffuse parenchymal disease; thus, factors other than increased solute load per residual nephron may contribute to the altered concentrating and diluting ability seen in chronic renal disease.

\section{Acknowledgment}

We are indebted to Sybil Gordon, Ophelia Kuever, Marianne Finklestein, and John Steppe for technical assistance, to Arnold Bragan for assistance in animal care, and to Doris Davis and Doris Blackmon for clerical help in preparing the manuscript. The surgical assistance of Dr. Emanuel Nosowsky in performing the subtotal nephrectomies and statistical compilation performed by Dr. Edward F. Gocka are also gratefully acknowledged.

\section{References}

1. Platt, R. Structural and functional adaptation in renal failure. Brit. med. J. 1952, 1, 1313.

2. Bricker, N. S., R. R. Dewey, H. Lubowitz, J. Stokes, and T. Kirkensgaard. Observations on the concentrating and diluting mechanisms of the diseased kidney. J. clin. Invest. 1959, 38, 516.
3. McCance, R. A. The excretion of urea, salts and water during periods of hydropaenia in man. $\mathrm{J}$. Physiol. (Lond.) 1945, 104, 196.

4. Rapoport, S., W. A. Brodsky, C. D. West, and B. Mackler. Urinary flow and excretion of solutes during osmotic diuresis in hydropenic man. Amer. J. Physiol. 1949, 156, 433.

5. Brodsky, W. A., and S. Rapoport. The mechanism of polyuria of diabetes insipidus in man. The effect of osmotic loading. J. clin. Invest. 1951, 30, 282.

6. Kleeman, C. R., F. H. Epstein, and C. White. The effect of variations in solute excretion and glomerular filtration on water diuresis. J. clin. Invest. 1956, 35, 749.

7. Bricker, N. S., S. W. Kime, Jr., P. A. F. Morrin, and $T$. Orlowski. The influence of glomerular filtration rate, solute excretion and hydration on the concentrating mechanism of the experimentally diseased kidney in the dog. J. clin. Invest. 1960, 39, 864.

8. Hinman, F. The condition of renal counterbalance and the theory of renal atrophy of disuse. J. Urol. (Baltimore) 1943, 49, 392.

9. Bricker, N. S., S. Klahr, and R. E. Rieselbach. The functional adaptation of the diseased kidney. I. Glomerular filtration rate. J. clin. Invest. 1964, 43, 1915.

10. Franklin, S. S., and J. P. Merrill. The kidney in health; the nephron in disease. Amer. J. Med. $1960,28,1$.

11. Bricker, N. S., P. A. F. Morrin, and S. W. Kime, Jr. The pathologic physiology of chronic Bright's disease. Amer. J. Med. 1960, 28, 77.

12. Bricker, N. S. Chronic progressive renal disease: pathologic physiology and relation to treatment. Progr. cardiovasc. Dis. 1961, 4, 170.

13. Nosowsky, E. E. Experimental renal insufficiency in dogs. J. Urol. (Baltimore) 1963, 89, 9.

14. Peters, J. H. The determination of creatinine and creatine in blood and urine with photoelectric colorimeter. J. biol. Chem. 1942, 146, 179.

15. Smith, H. W., N. Finkelstein, L. Aliminosa, B. Crawford, and M. Graber. The renal clearances of substituted hippuric acid derivatives and other aromatic acids in dog and man. J. clin. Invest. 1945, 24, 388.

16. Kibrick, A. C., M. R. Ross, and S. V. Scupp. Determination of urea nitrogen in whole blood by heating in a pressure cooker. Analyt. Chem. 1953, $25,364$.

17. Skeggs, L. T. An automatic method for colorimetric analysis. Amer. J. clin. Path. 1957, 28, 311.

18. Dixon, W. J., and F. J. Massey, Jr. Introduction to Statistical Analysis. New York, McGraw-Hill, 1957.

19. Houck, C. R. Statistical analysis of filtration rate and effective renal plasma flow related to weight and surface area in dogs. Amer. J. Physiol. 1948, 153, 169. 
20. Chow, G. C. Tests of equality between sets of coefficients in two linear regressions. Econometrica 1960, 28, 591.

21. Bradford, J. R. The results following partial nephrectomy and the influence of the kidney upon metabolism. J. Physiol. (Lond.) 1918, 23, 415.

22. Hayman, J. M., Jr., N. P. Shumway, P. Dumke, and M. Miller. Experimental hyposthenuria. J. clin. Invest. 1939, 18, 195.

23. Platt, R., M. H. Roscoe, and F. W. Smith. Experimental renal failure. Clin. Sci. 1952, 11, 217.

24. Kolberg, A. Relations of renal tubular and glomerular function as influenced by 75 per cent reduction of nephron number. A pathophysiological study. Scand. J. clin. Lab. Invest. 1959, 11, 11.

25. Baldwin, D. S., H. J. Berman, H. O. Heinemann, and H. W. Smith. The elaboration of osmotically concentrated urine in renal disease. J. clin. Invest. 1955, 34, 800.

26. Dorhout-Mees, E. J. Relation between maximal urine concentration, maximal water reabsorption capacity, and mannitol clearance in patients with renal disease. Brit. med. J. 1959, 1, 1159.

27. Kleeman, C. R., D. A. Adams, and M. H. Maxwell. An evaluation of maximal water diuresis in chronic renal disease. I. Normal solute intake. J. Lab. clin. Med. 1961, 58, 169.

28. Bricker, N. S., E. J. Dorhout-Mees, S. Klahr, Z. B. Orlowski, R. E. Rieselbach, and L. E. Todd. The rate limiting and adaptive events in tubular and glomerular functions of the chronically diseased kidney. Proc. 2nd Int. Congr. Nephrol. 1964, 39. 29. Klahr, S., Z. Orlowski, C. Voute, E. J. DorhoutMees, and N. S. Bricker. On the nature of the concentrating defect in bilateral renal disease. Clin. Res. 1962, 10, 250.

30. Franklin, S. S., J. F. Niall, and J. P. Merrill. The influence of solute load on the isosthenuria of renal disease. J. clin. Invest. 1959, 38, 1005.

31. Adams, D. A., C. R. Kleeman, L. H. Bernstein, and M. H. Maxwell. An evaluation of maximal water diuresis in chronic renal disease. II. Effect of variations in sodium intake and excretion. J. Lab. clin. Med. 1961, 58, 185.

32. Levy, S. E., and A. Blalock. The effects of unilateral nephrectomy on the renal blood flow and oxygen consumption of unanesthetized dogs. Amer. J. Physiol. 1938, 122, 38.

33. Berliner, R. W., N. G. Levinsky, D. G. Davidson, and $M$. Eden. Dilution and concentration of the urine and the action of antidiuretic hormone. Amer. J. Med. 1958, 24, 730.

34. Davis, J. O., and N. W. Shock. The effect of theophylline ethylene diamine on renal function in control subjects and in patients with congestive heart failure. J. clin. Invest. 1949, 28, 1459.

35. Kleeman, C. R., R. Cutler, M. H. Maxwell, L. Bernstein, and J. T. Dowling. Effect of various diuretic agents on maximal sustained water diuresis. J. Lab. clin. Med. 1962, 60, 224.

36. Buchborn, E., S. Anastasakis, and H. Edel. Zum Wirkungsmechanismus des Euphyllin als Diureticum. Klin. Wschr. 1961, 39, 784. 